\title{
Accessibility and utilization of modern health care among rural community in Ethiopia: The case of Bako district, Western Oromia: Community based descriptive cross-sectional study
}

\author{
Tadesse Abdisa Abdisa \\ Wollega University \\ Zelalem Desalegn \\ Wollega University \\ Melese Chego Cheme ( $\sim$ melese_chego@yahoo.com ) \\ Wollega University https://orcid.org/0000-0002-0237-4028
}

\section{Research note}

Keywords: Health seeking behavior, Access, Bako district, Ethiopia

Posted Date: October 10th, 2019

DOl: https://doi.org/10.21203/rs.2.15837/v1

License: (c) (i) This work is licensed under a Creative Commons Attribution 4.0 International License.

Read Full License 


\section{Abstract}

Objectives: Knowing determinants of health seeking behaviors of families is significant in assuring access and utilization of health services. Less is known on the seeking behaviors and access of modern health services among populations in rural settings in Ethiopia. The general Objective of the study is to assess health care seeking behavior (Utilization) and associated factors among the community of in Bako Tibe District, Ethiopia. Community based descriptive cross-sectional study design was used on 750 head of the residents of $\geq 18$ years old. Multistage sampling technique was used to get the households and data was collected by interview using structured questionnaire and analyzed using SPSS version 24 . Binary and multiple logistic regression analysis were used to identify the factors associated with the health seeking behavior. Results: 495(66\%) reported having morbidity and level of health care seeking behavior was $78.6 \%$ of which $66 \%$ sought care from government facilities. Sex of respondent, residence, family size, educational status, monthly income, disease condition, Perceived severity \& access to needed health information were found to be significant associated factors of healthcare seeking behavior of the respondents in multiple logistic regression analysis. Keywords: Health seeking behavior, Access, Bako district, Ethiopia

\section{Background}

Health seeking behavior can be conceptualized health service utilization as outcome or the process of seeking care. Health care Utilization behaviors should be seen in wider contexts of social capital as communities' engagement in the health system and services. (1-4). Knowing determinants of health seeking behaviors of families will be essential in assuring access and utilization of health services. Less is known on the seeking behaviors and access of modern health services among populations in rural settings in Ethiopia $(5,6)$.

Studies indicate that, people who are in better socioeconomic status are in better utilization at household level. Study in rural Bangladesh showed that households in higher wealth quartile had better utilization of maternal and child health services and Relative poverty level played a key role in utilization of health services. Study from national survey data in Nigeria indicated that education level of individuals were main factor for individual level predictor of maternal service utilization and socioeconomic status and residence status were main predictors of utilization of services at household and community levels respectively (7-9). Usually, the poor seeks care from government facilities compared to the middle class and wealthy (10-14).

Contrary to this, on study India, the higher and the middle income individuals used public facilities more than the lower income and the lower income utilized more private facilities. Seeking care from private facilities in respective of income status may imply concerns of quality of care in public facilities. In South Africa, most rural and urban residents claimed adequate access to health care but they still face difficulties in actual receiving of care $(12,15,16)$. 
According to study in Uganda, private health care providers' role is increasing in Uganda and other subSaharan African countries implying regulatory mechanisms, quality and affordability of services $(18,19)$. Studies from east African countries show that, preference for modern health care is almost universal but differed for different socioeconomic classes. Delay to seek care was higher for adult related cases and poorer groups. (20-24).

Studies also show that, during emergency and critical illness proximity of services is the main issue to choice facility and in case of chronic illness cost of service becomes a main concern to determine type of provider $(23,25,26)$. This study intended to determine the level of health care seeking behavior of the community and to identify factors that affect healthcare seeking behavior of the community in Bako Tibe District. Figure 1 below shows the conceptual framework of the study.

Figure 1. Conceptual Framework for Healthcare Seeking Behavior modified from Andersen's behavioral model.

\section{Materials And Methods}

\section{Study setting:}

This study was conducted in Bako Tibe District, West Shewa Zone of Oromia Region, Ethiopia. Bako Tibe Woreda has 28 rural kebeles and 4 urban kebeles with an average of 4.7 persons per household. The total population of the Woreda by the year 2016 is $34,004(6,710$ urban HHs \& 27,294). The majority of the population is ethnically Oromo and Christian in religion. This district has 5 health government health centers one primary hospital and about 25 health posts.

\section{Study Design and period:}

\section{Community based descriptive cross-sectional study design was used from August to September 2017.}

\section{Population:}

All households residing in Bako Tibe district were considered as the source population and Household respondents who participated in the study were considered as study populations.

\section{Inclusion and exclusion criteria:}

\section{Head of the households or family representatives of $\geq 18$ years old who resided in the district for six or more months before data}




\section{collection period.}

\section{Sample Size determination:}

Sample size was calculated using single finite population proportion formula with the following assumptions: $58.4 \%$ general prevalence of healthcare seeking behavior for households, from a study (Begashaw B. et al 2016), 95\% confidence level, 5\% margin of error, and 5\% estimated non-response rate, design effect of 2 , the required sample size was 750 (177 urban and 573 rural). Considering $5 \%$ estimated non-response rate and a design effect of $2, n=783$

\section{Sampling Procedure:}

Multistage sampling technique was used to get the households. The district was classified into two strata; urban and rural. Eight kebeles were included in the study ( 2 urban and 6 rural). The kebeles were selected using simple random sampling methods. Systematic sampling technique was employed for households' selection.

\section{Data Collection Procedure:}

Data was collected by interview using structured questionnaire. The data collection tool was prepared in English and translated to local language (Afaan Oromo). To check reliability it was translated back to English.

\section{Variables:}

The dependent variable was healthcare seeking behavior and the exposure variables were age, sex, education, occupation, marital status, family income, distance from health facility, cost of healthcare service, duration of illness, perceived severity of illness, use of traditional medicine, residence and selfmedications.

\section{Data Analysis and interpretation:}

\section{Data was entered in Epi data version 3.1, transported to SPSS version 20 and analyzed using it. Descriptive and analytical statistics were calculated. Binary and multiple logistic regression analysis were used to identify the factors}




\section{associated with the health seeking behavior. Crude and adjusted Odds ratios were used to determine strength of association at 95 Confidence level and error $(=5 \%)$. Summaries of the result were presented by textual, tables and graphs.}

\section{Results}

\section{Socio-demographic characteristics:}

Seven hundred fifty (95.8\%) participants, of which $189(25 \%)$ urban and $561(75 \%)$ rural participated in the interview. Males accounted for 472(62.9\%) and about 446(59.5\%) of the respondents were farmers. About $452(60.3 \%)$ of households had family size greater than four. Only $252(33.6 \%)$ of households have Community health insurance and majority of the respondents are Oromo 704(93.8\%).

\section{Health care seeking behavior:}

Among all respondents, $495(66 \%)$ reported having morbidity of which $335(67.67 \%)$ of the illness was perceived to be acute illness. Among those who reported morbidity, perceived severity of illness was $351(70.9 .8 \%)$. Distance from modern health facility (Public health center, private clinic \&health post) is less than $10 \mathrm{~km}$ far from all households. The general level of health care seeking behavior was $78.6 \%$. About $66 \%$ of the respondents sought care from government facilities, the main type of facility being health center which was sought by about $52 \%$ of all those sought care. Only $70 \%$ of those who sought care reported immediate seeking of care after the perception of the illness.

\section{Factors associated with health care seeking behaviors of households:}

Result of bivariate analysis to identify the candidate variables for multinomial logistic regression analysis is indicated below (Table 1).

From adjusted model in multinomial logistic regression analysis below (Table 2), sex, residence, family size, educational status, income, disease condition, Perceived severity andaccess to needed health information were found to be significant factors for seeking healthcare of the respondents in multiple logistic regression analysis. Accordingly, the odds of health seeking behavior among male participants was about 5.7 times higher than female participants (AOR $=5.7,95 \% \mathrm{Cl}: 3.0,11.0$ ) \& the odds of healthcare seeking behavior among urban households was about 9.5 times greater than healthcare seeking behavior of rural households (AOR, 9.5; $95 \% \mathrm{Cl}, 3.6,25.5)$. Healthcare seeking behavior among 
households with < = 4 family sizes were approximately 6 times greater than households with $>4$ family sizes (AOR $=5.8,95 \% \mathrm{Cl}: 2.6,12.8)$. Households with monthly income above 1,170 birr were about 9 times more likely to seek healthcare as compared to those who earn less than 1,170 ( $\mathrm{AOR}=8.97,95 \% \mathrm{Cl}$ : $4.5,17.7)$. Healthcare seeking behavior was approximately 2.8 times greater among household having secondary education \& 8.5 times greater among households graduated from College and above when compared with illiterate ones $(\mathrm{AOR}=2.8,95 \% \mathrm{Cl}: 1.02,7.5) \& \mathrm{AOR}=8.5,95 \% \mathrm{Cl}: 1.9,38.9$ respectively). The odds of health seeking behavior among those who perceived serious illness (Perceived severity) was about 3 times higher (AOR, 3.3; $95 \% \mathrm{Cl}, 1.7,6.4$ ) than those who didn't. Households who perceived illness (disease condition) as acute were about $2.8(\mathrm{AOR}=2.8,95 \% \mathrm{Cl}, 1.5,5.2)$ times more likely to seek healthcare than those who perceived chronic illness. Households who have access to needed health information of healthcare for perceived illness were about 3.7 time more likely to seek healthcare than those who had no access to needed health information of healthcare ( $A O R=3.7,95 \% \mathrm{Cl}, 1.9,7.4)$. (Table 2).

\section{Discussion}

Since past 3 decades, Ethiopian strived to increase the coverage of the modern health care for massive populations particularly the rural and remote communities through different strategies and potential health service coverage reached beyond $90 \%(27,28)$. As to the health seeking behavior of the community, about $78 \%$ of the respondents sought care for their illness. This finding is relatively higher than studies conducted in the country elsewhere. This can be the attributed to the decentralized and community based health care delivery strategy in the country. However still significant proportion (22\%) of the population did not seek care for their perceived illness and about $30 \%$ who sought care were late in seeking care $(4,5,8)$.

One of the impressive findings of the study is that all of the households had access to physical facilities (Public health center, private clinic and health post) within $10 \mathrm{~km}$ of distance. Proximity of basic health care facilities is among key factors that utilization of modern health care. The structurally decentralized facilities should be functionally accessible in terms of quality and cost of health services. This finding is in agreement with study in South Africa which indicate adequate access of facilities for health care although there is difficulty in actual access of care (11).

The health care facilities visited by the care seekers varied among the respondents. Majority of them $(66 \%)$ visited government facilities. Health center, which is expected to provide basic health promotive, disease preventive and curative services, has been visited by majority of the participants (52\%). This is in agreement with the policy direction of the country as the essential health services should be available to all population with in $10 \mathrm{~km}$ diameter. However, the proportion of the respondents who sought care from health post is very low (below $2 \%$ ). The utilization of private health care institutions also contributed for the second major share, $23.9 \%$. This implies the increasing share of private health care providers in preference of seeking modern health care by the community. This is contrary to the existing practice where there is limited support and regulation to the private health services in the country. The fact that this share is increasing may imply that the government facilities are not embarking on quality of health 
care that satisfy the health care needs of the country. This has been evidenced by other studies globally $(9,11,15)$.

Health seeking was affected by different level factors. Males seek care 6 times more than females. This is strong association which shows huge gender imbalance in health care utilization in the area. This can be attributed to the sociocultural, economic, burdens Ethiopian women face in the livelihood of the households (EDHS). Ample studies globally also show similar pattern of imbalance in health seeking behavior among male and female but in different level of strength $(1,2$, and 14$)$. This study also identified that urban residents had 9.5 times better health care seeking behaviors than the rural ones. This can be justified by better access of health information and access of health facilities of the urban population than the rural.

\section{Conclusions}

The overall healthcare seeking behavior of households for perceived illness was satisfactory. The private health sectors (clinics) are contributing a significant role in access of health care for the community in the study area and demands strong support from the public sector. Sex, residence, family size, monthly income, educational status of participants, perceived severity of illness, condition of illness and access to needed health information showed a significant association with health care seeking behavior. Family and community level interventions should be enhanced and CBHI should be scaled up especially the rural population.

\section{Limitations}

seasonal variation, recall bias and social desirability bias might have affected the study.

\section{Declarations}

\section{Abbreviations:}

EDHS: Ethiopian demographic and health survey; US: United States; Cl: Confidence interval; AOR: Adjusted odds ratio; COR: Crude Odds Ratio; CBHI: Community based health insurance.

\section{Ethics approval and consent to participate:}

Ethical clearance was obtained from Wollega University ethical clearance committee. Written consent was obtained from the respondents to participate in the study and confidentiality was kept along all process of this research work. The purpose of the study was also communicated and there is no serious 
harm the study poses to the participant expect a time they waste for interview. They were also told as they can withdraw from the study in middle of the responses if they think it is not fair to them.

\section{Consent for publication:}

Not applicable.

\section{Availability of data and material:}

The data sets during and/or analyzed during the current study available from the corresponding author on reasonable request.

\section{Competing interests:}

The authors declare that they have no competing interests.

\section{Funding:}

Fund was not received from any firm or individuals.

Authors' contributions:All authors have participated in the research work and have read and approved the manuscript.

TA generated the research question, developed proposal, supervised data collection process, analyzed data and prepared research report.

$Z D$ was main/senior advisor of the research proposal development and data analysis process.

$M C$ was co-advisor of the research proposal development and data analysis process.

\section{Acknowledgements:}

Our thanks goes to Wollega university, college of medical and health sciences, department of public health and office of postgraduate studies of college of medical and health sciences, Bako district administration, Bako district health office for their support and provision of necessary information for this research. Lastly we acknowledge the contributions of data collectors and respondents.

\section{References}


1. Health insurance and health-seeking behavior: evidence from a Gwatkin DR. Health inequalities and the health of the poor: What do we know? What can we do? 2000;

2. Sara MacKian; A review of health seeking behaviour: Problems and prospects, University of Manchester Health Systems Development Programme.

3. Siddiqui MS, Siddiqui MS, Sohag AA. Health seeking behavior of the people; knowledge, attitudes and practices (KAP) study of the people of Urban Slum Areas of Karachi. Professional Med J Dec 2011;18(4): 626-631.

4. Cynthia Eka Fayuning Tjomiadi, Pattama Surit; Health Seeking Behavior: Concept Analysis, Advances in Health Science Research, volume 6, 2nd Sari Mulia International Conference on Health and Sciences (SMICHS 2017)

5. Central Statistical Agency (CSA) [Ethiopia] and ICF. 2016. Ethiopia Demographic and Health Survey 2016. Addis Ababa, Ethiopia, and Rockville, Maryland, USA: CSA and ICF.

6. Kimberly A. Greder, Yoshie Sano; Health-Seeking Behavior in Families, book chapter is available at Iowa State University Digital Repository: http://lib.dr.iastate.edu/hdfs_pubs/88

7. Amin R, Shah NM, Becker S. Socioeconomic factors differentiating maternal and child health seeking behavior in rural Bangladesh: A cross-sectional analysis. 2010;1-11.

8. Babalola S, Fatusi A. BMC Pregnancy and Childbirth beyond individual and household factors. 2009;13:1-13.

9. Bakeera SK, Wamala SP, Galea S, State A, Peterson S, Pariyo GW. International Journal for Equity in Community perceptions and factors influencing utilization of health services in Uganda. 2009;12.

10. Bhatia JC, Cleland J. Health-care seeking and expenditure by young Indian mothers in the public and private sectors. 2001;16(1):55-61.

11. Bourne PA. Socio-demographic determinants of Health care-seeking behaviour, selfreported illness and Self-evaluated Health status in Jamaica Socio-demographic determinants of Health care-seeking behaviour , self- reported illness and Selfevaluated Health status in Jamaica. 2014;(June 2009).

12. Deressa W. Treatment-seeking behaviour for febrile illness in an area of seasonal malaria transmission in rural Ethiopia. 2007;7:1-7.

13. Getahun A, Deribe K, Deribew A. Determinants of delay in malaria treatment- seeking behaviour for under-five children in south-west Ethiopia: a case control study. 2010;16.

14. Gelaw YA, Biks GA, Alene KA. Effect of residence on mothers ' health care seeking behavior for common childhood illness in Northwest Ethiopia: a community based comparative cross - sectional study. 2014;1-8. 
15. Gupta I, Dasgupta P. Health Seeking Behaviour in Urban Delhi: An Exploratory Study Health-seeking Behavior in urban Delhi: An Exploratory Study. 2016;(January 2013).

16. Hoeven M Van Der, Kruger A, Greeff M. Differences in health care seeking behaviour between rural and urban communities in South Africa. 2012;1-9.

17. Insaf TZ, Jurkowski JM. S OCIOCULTURAL F ACTORS I NFLUENCING D ELAY IN S EEKING R OUTINE H EALTH C ARE AMONG L ATINAS: A C OMMUNITY -B ASED P ARTICIPATORY R ESEARCH S TUDY There is a paucity of research on Latinos living in new Latino destinations in health literature 4 and there has been a call for more public health research on Latinas to improve the understanding of. 0414.

18. Konde-lule J, Gitta SN, Lindfors A, Okuonzi S, Onama VON, Forsberg BC. Private and public health care in rural areas of Uganda. 2010;2-9.

19. Lawson D, Lawson D. Development Economics and Public Policy WORKING PAPER SERIES Is it Just Income and User Fees That Determinants of Health Seeking Behaviour in Uganda - Is it Just Income and User Fees That Are Important? 2004;(6):131.

20. Mebratie AD, Poel E Van De, Yilma Z, Abebaw D, Alemu G, Bedi AS. Healthcareseeking behaviour in rural Ethiopia: evidence from clinical vignettes. 2014;

21. Muriithi MK. THE DETERMINANTS OF HEALTH-SEEKING BEHAVIOR IN A NAIROBI SLUM , KENYA. 2013;9(8):151-64.

22. Musoke D, Boynton $P$, Butler C, Musoke MB. Health seeking behaviour and challenges in utilising health facilities in Wakiso district, Uganda. 2014;14(4).

23. Pradesh U, Raza WA, Poel E Van De, Panda P, Dror D, Bedi A. Healthcare seeking behaviour among self-help group households in Rural Bihar. BMC Health Services Research; 2016;1-13.

24. Taffa N, Chepngeno G. Determinants of health care seeking for childhood illnesses in Nairobi slums. 2005;10(3):240-5.

25. Ukwaja KN, Alobu I, Nweke CO, Onyenwe EC. Healthcare-seeking behavior , treatment delays and its determinants among pulmonary tuberculosis patients in rural Nigeria: a cross- sectional study. 2013;1-9.

26. Senbeto et al.: Appropriate health-seeking behavior and associated factors among people who had cough for at least two weeks in northwest Ethiopia: a population-based crosssectional study. BMC Public Health 2013 13:1222.

27. Rose Ann Dominic , Shashidhara Y.N. , Malathi G. Nayak; health seeking behavior of rural adults, NUJHS vol. 3, no.3, September 2013, issn 2249-7110.

28. UN, 2015; transforming our world: THE 2030 AGENDA FOR SUSTAINABLE DEVELOPMENT. 


\section{Tables}

Table 1: Binary logistic regression on healthcare seeking behaviors of households in Bako Tibe district, Aug-Sep. 2017. 


\begin{tabular}{|c|c|c|c|c|}
\hline \multirow[t]{2}{*}{ Variables } & \multirow[t]{2}{*}{$\begin{array}{l}\mathrm{N}(\%) \\
\mathrm{n}=495\end{array}$} & \multirow{2}{*}{$\begin{array}{l}\text { Health } \\
\text { behavior } \\
\text { Yes (\%) }\end{array}$} & care seeking & \multirow[b]{2}{*}{ COR $(95 \% \mathrm{CI})$} \\
\hline & & & No (\%) & \\
\hline Age & & & & \\
\hline $18-30$ & $222(44.8)$ & $46(20.7)$ & $176(79.3)$ & 1.00 \\
\hline $31-45$ & $194(39.2)$ & $49(25.3)$ & $145(74.7)$ & $0.8(0.5,1.2)$ \\
\hline $46-59$ & $59(11.92)$ & $11(18.60$ & $48(81.4)$ & $1.1(0.55,2.4)$ \\
\hline $60+$ & $20(4)$ & 0 & $20(100)$ & 00 \\
\hline \multicolumn{5}{|l|}{ Sex of respondents } \\
\hline Male & $289(58.4)$ & $40(13.8)$ & $249(86.2)$ & $2.9(1.9,4.6) * *$ \\
\hline Female & $206(41.6)$ & $66(32)$ & $140(68)$ & 1.00 \\
\hline \multicolumn{5}{|l|}{ Residence } \\
\hline Rural & $393(79.4)$ & 94(23.9) & $299(76.1)$ & 1.00 \\
\hline Urban & $102(20.6)$ & $12(11.8)$ & $90(88.2)$ & $\begin{array}{l}2.4(1.24,4.5) \\
*\end{array}$ \\
\hline \multicolumn{5}{|l|}{ Occupation } \\
\hline House Wife & $13(2.6)$ & $6(46.2)$ & $7(53.8)$ & 1.00 \\
\hline Farmer & $281(56.7)$ & $76(27)$ & $205(73)$ & $2.31(0.75,7.1)$ \\
\hline Merchant & $62(12.5)$ & $13(21)$ & $49(79)$ & $\begin{array}{l}3.23(0.93 \\
113)\end{array}$ \\
\hline Private & $49(9.8)$ & $6(12.2)$ & $43(87.8)$ & $\underset{*}{6.1(1.5,24.5)}$ \\
\hline Student & $36(7.2)$ & 0 & $36(100)$ & \\
\hline Daily laborer & $9(1.8)$ & $2(22.2)$ & $7(77.8)$ & $3.0(0.4,20.3)$ \\
\hline Government employee & $45(9)$ & $3(6.7)$ & $42(93.3)$ & $12.0(2.4,59.5)$ \\
\hline \multicolumn{5}{|l|}{ Religion of respondents: } \\
\hline Orthodox Christians & $132(26.7)$ & $30(22.70$ & $102(77.3)$ & 1.00 \\
\hline Evangelical Christians & $287(58)$ & $60(20.9)$ & $227(79.1)$ & $1.1(0.7,1.8)$ \\
\hline Wakefata & $13(2.6)$ & $3(23.1)$ & $10(76.9)$ & $0.98(0.25,3.8)$ \\
\hline Muslim & $63(12.7)$ & 13(20.6) & $50(79.4)$ & $1.1(0.5,2.4)$ \\
\hline \multicolumn{5}{|l|}{ Marital status } \\
\hline Single & $51(10.3)$ & $15(29.4)$ & $36(70.6)$ & 1.00 \\
\hline Married & $419(84.6)$ & $82(19.6)$ & $337(80.4)$ & $1.7(0.9,3.3)$ \\
\hline Widowed & $21(4.2)$ & $5(23.8)$ & $16(76.2)$ & $1.3(0.4,4.3)$ \\
\hline Divorced & $4(0.8)$ & $4(100)$ & 0 & 00 \\
\hline \multicolumn{5}{|l|}{ Family size } \\
\hline$<=4$ & $200(40.4)$ & $32(16)$ & 168(84) & $1.76(1.1,2.8) *$ \\
\hline $\begin{array}{l}>4 \\
\text { Ethnic group }\end{array}$ & 295(59.6) & $74(25.1)$ & $221(74.9)$ & 1.00 \\
\hline Oromo & $464(93.7)$ & $98(21.1)$ & $366(78.9)$ & 1.00 \\
\hline Amhara & $16(3.22)$ & $4(25)$ & $12(75)$ & $0.8(0.3,2.5)$ \\
\hline Gurage & 15(3.03) & $4(26.7)$ & $11(73.3)$ & $0.7(0.23,2.4)$ \\
\hline \multicolumn{5}{|l|}{ Monthly income(in Birr) } \\
\hline$<1,170$ & 247(49.9) & $84(34)$ & 163(66) & 1.00 \\
\hline$>=1,170$ & $248(50.1)$ & $22(8.9)$ & $226(91.1)$ & 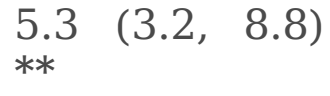 \\
\hline \multicolumn{5}{|l|}{ Educational status } \\
\hline Illiterate & $102(20.6)$ & $30(29.4)$ & $72(70.6)$ & 1.00 \\
\hline Primary & 207(41.8) & $48(23.2)$ & 159(76.8) & $1.4(0.8,2.4)$ \\
\hline Secondary & $141(28.4)$ & $24(17)$ & $117(83)$ & $2.0(1.1,3.8) *$ \\
\hline College $\&$ above & $45(9.1)$ & $4(8.9)$ & $41(91.1)$ & $4.3(1.4,12.9) *$ \\
\hline Perceived severity & & & & \\
\hline
\end{tabular}




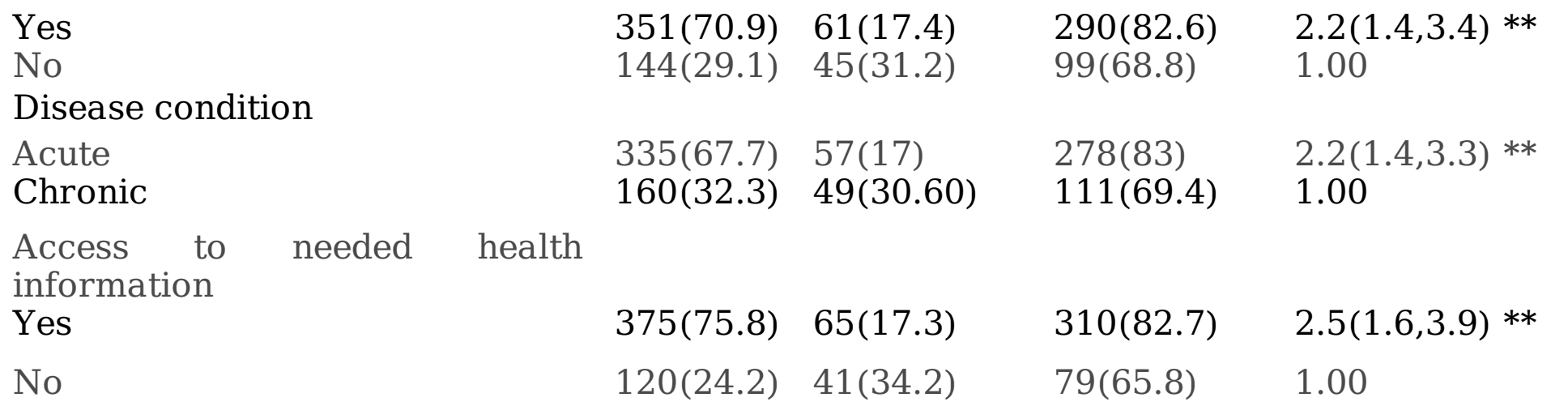

NB: $1.00=$ reference category, $* *$ p-value $<0.001$, *p-value $\leq 0.05$.

Table 2: Multiple Logistic regression on healthcare seeking behaviors of households in Bako Tibe district, Aug-Sep 2017. 


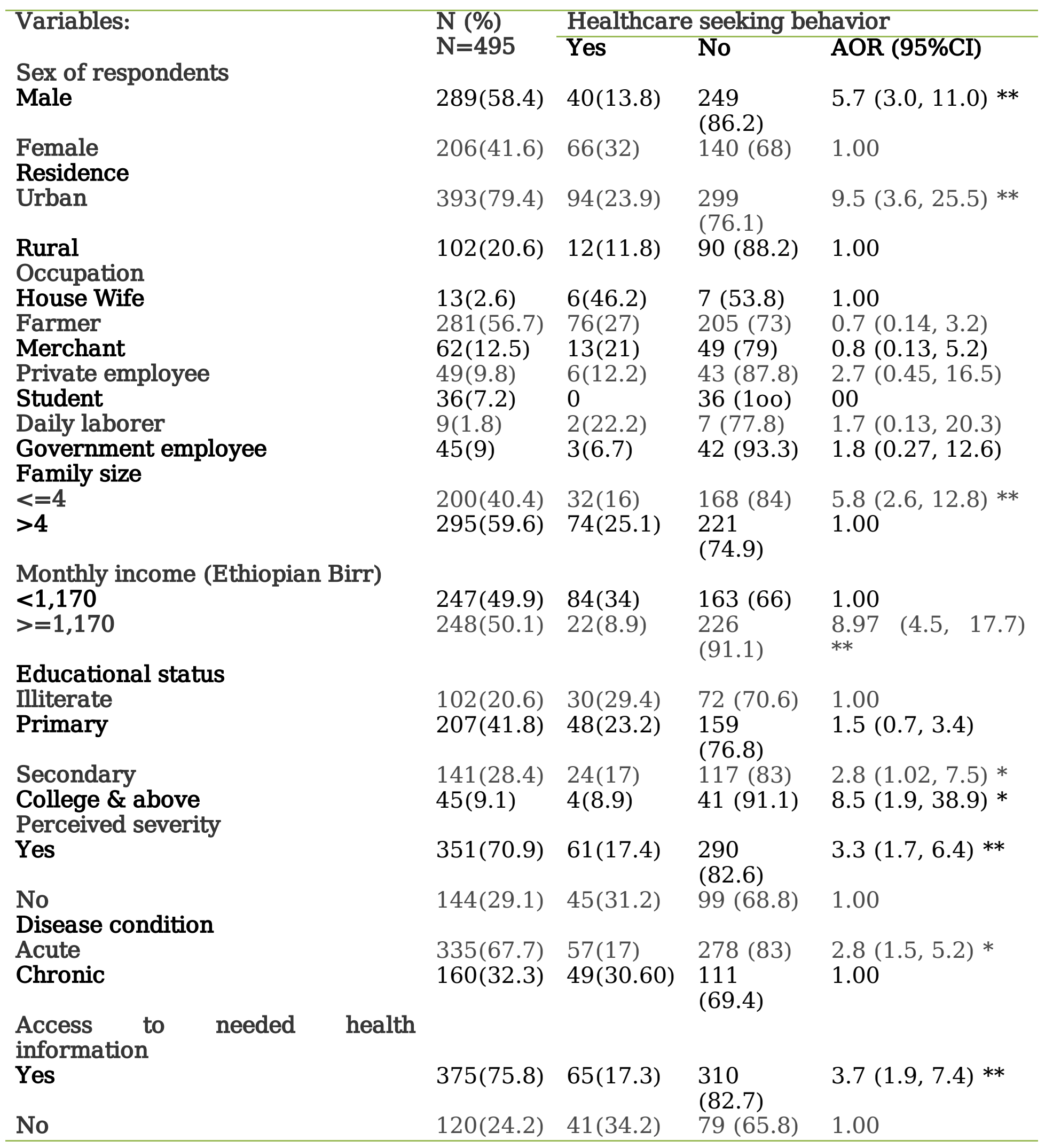

NB: $1=$ reference category, $* *$ p-value $<0.001, * p$-value $\leq 0.05$.

Figures 


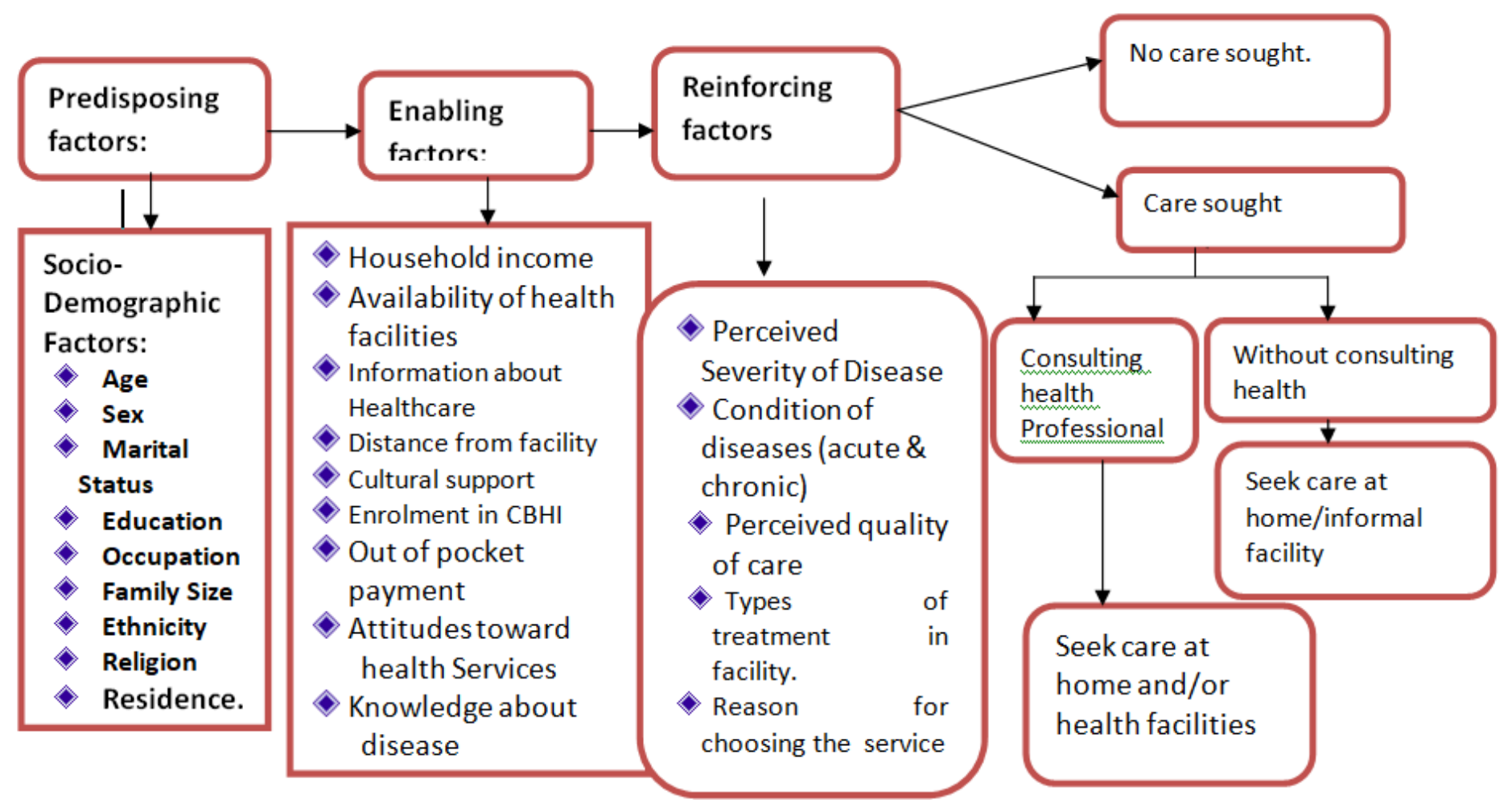

Figure 1

Conceptual Framework for Healthcare Seeking Behavior modified from Andersen's behavioral model. 